\title{
GLOBES: 400 YEARS OF EXPLORATION, NAVIGATION, AND POWER -
}

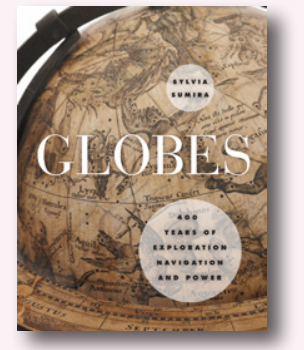

By Sylvia Sumira.

The University of Chicago Press, 2014.

224 pages, 120 color plates. $\$ 45.00$,

cloth.

ISBN: 978-0-226-13900-5

Review by: Mark Denil

Globes: 400 Years of Exploration, Navigation, and Power, by the respected professional globe-conservator Sylvia Sumira, is a fairly comprehensive and concise overview of globes and their makers from the late $-15^{\text {th }}$ through the late $-19^{\text {th }}$ centuries. It is touted as a brief history of globe making, and, within its declared limits, it delivers on that promise. Globes is built around a museum-quality photo parade of scarce, fragile, precious, delightful, and wondrous artifacts supported by succinct gallery-walllabel-like texts, and it wraps that exhibition with equally succinct essays and glossaries to provide context and accessibility.

Globes are seductive objects: every one, from the newest and cheapest (say, an inflatable beach ball) to the rarest and most costly (many examples of which populate the pages of Globes), carries a special je ne sais quoi; rather like a cross between a map and a Ukrainian pysanka. Globes tend to be difficult to make, awkward to store, and a bit of a bother to use; they are usually too small to show the detail one wants or too large to handle conveniently. Most are absurdly delicate, and those that are not tend to annoyingly trade away precision for ruggedness. Still, their seductiveness is undeniable (at a quick count, I, myself, have at least twenty here in my apartment as I write), and the examples displayed in Globes attests to a long history of their siren-like appeal.

This University of Chicago Press book has a decent heft, with firm board covers in dark blue cloth, and reasonably opaque, Permanence of Paper standards mark pages of a good weight. A full bleed detail photo of a globe graces each dust jacket face: a celestial globe on the front and a terrestrial on the back.
The body of the book is divided into two main sections, plus a preface and four end-matter sections. The first main section is composed of three chapters: "The Parts of a Globe," "A Brief History of Globes," and "The Making of Globes."

The two-page spread entitled "The Parts of a Globe" displays unattributed engravings of a celestial/terrestrial globe pair, with the major features labeled with call-outs. As it happens, the labeled parts of the two are identical, save that the celestial sports an Equinoctial Line in lieu of the terrestrial's Equator, and a Colure, which the other lacks. It is not entirely clear why this chapter is so far separated from the useful two-page Glossary that is tucked away near the volume's end, in a sort of betwixt and between place after the main body but before the Bibliography, Picture Credits, and Index.

"A Brief History of Globes" fills eighteen pages with two-column text and twenty-two illustrations, six of which are full page. This chapter is the core historical narrative; it is sprinkled with frequent references to individual globes that appear in the second main section of the book ("The Globes"). One is at first tempted to read the narrative in parallel with reading the blurbs on the individual globes, but after a few pages of the narration the references start to bunch up and the connections become less specific, making that plan unworkable.

The eight pages of "The Making of Globes" are very informative. This is a topic on which one would expect the author's expertise to shine, and she does not disappoint. This is not a how-to manual on globe building, nor is it a treatise on globe restoration, but it is a general discussion of what is going on inside the ball by someone who has looked inside more than a few of them, and of the situation on the outside by someone who has often had to fix the ravages of more time than the maker probably ever expected the artifact to survive.

We now come to the main event: the section entitled simply, "The Globes." The primary focus of the collection is on printed globes, but there is a smattering of manuscript and engraved-metal globes to round out the overview. 
The author enjoyed a long association with the British Museum, and the lion's share (forty-one) of the globes on display resides in that institution. A further eleven are from other British collections, with seven more held by museums in other countries.

The photography is excellent. Each globe is displayed in a full-page, full-length portrait, including its stand (where one exists), and more than half of the globes also have at least one full-bleed, two-page-spread detail photo as well.

The page layout in this section is formal, and rather old-fashioned; quite in keeping with the dates of the artifacts. There are generous, symmetrical side margins, with a clear inch and three-quarters deep space across the top. The five-line exhibit identification heading is center justified, and below it is a five-inch wide, centered and fully justified text block that starts just an inch and a half above the page center. Each page in this section has this good, solid, formally balanced $18^{\text {th }}$ century page architecture: elegant, refined, and self-assured.

Contrast this formality to the (very nice) two-column, flush left/ragged right text in the first section, or the way the Preface has a justified text block similar to "The Globes" section, but with its heading and text placed flush, well over to the left. There is a clear sectional differentiation and hierarchy expressed in the page layouts, and we are left in little confusion as to what the author expects us to see as the serious work. I think a tip of the hat to Maggi Smith, the designer, is in order-and while we are at it, to the photographer, Elizabeth Hunter, as well.

Globes: 400 Years of Exploration, Navigation, and Power, is a sumptuous work providing excellent views of a large number of exquisite artifacts, and secondarily offering a historical horizon into which each globe can be placed. If you want to have a good look at globes that you, in all probability, would never otherwise have ever seen, then this is the book for you. Unfortunately, Ms. Sumira's writing on history does not do justice to the globes and their photographs (and, I assume, in many cases, her own restoration work). No editor is mentioned in the credits or preface, and she is sorely missed.

The problem lies, in part, with what one might call some rather peculiar grammatical constructs the author employs, constructs which make sorting out things like pronouns something of a puzzle and making for a somewhat staccato narrative flow. Most individual instances are just niggling, but far too often I found myself halting in mid-sentence to try to worry out just who "he" might be, or to find myself running full tilt into a new topic in the middle of a sentence.

The author especially seems to have a bit of a rocky time with interjected explanations: her discussion of rhumb lines on a Mercator globe is a case in point. First, she launches, without warning, into the topic of loxodromes in the second half of a mid-paragraph sentence that started off being about new discoveries in Asia. She then quickly (and not too clearly) tells us what rhumb lines are, and mentions their use, before she then brings up portolan charts. After observing that portolans were not constructed on a geometrical base, but that the rhumbs on them were shown as straight, she then says that they spiral to the poles on a globe. (Really? A rhumb on a Mercator projection does, but who knows where a straight line on a map with no geometric base actually goes? It could wander just about anywhere.) After this ten-line aside, the paragraph then abruptly drops the topic and closes with the line: "In 1551 Mercator published a companion celestial globe." What a wild ride through a cobbled-up paragraph!

The majority of this grammatical fluffiness is in "A Brief History of Globes," although some examples creep into the text in "The Globes" as well. Clearly the author is on much firmer ground in the chapter "The Making of Globes," which is, as already mentioned, well written.

All in all, Globes: 400 Years of Exploration, Navigation, and Power is an interesting and worthwhile book. Delectable photos of exquisite artifacts are its main strength, but the information contained (and especially the globe-making chapter) raises it out of the dread coffee table book league. The book is about globes: don't expect much about exploration, navigation, or power. One suspects that the subtitle was just tacked on by the publishers, because, hey, everything has a subtitle these days. List price for the hard copy book is $\$ 45$, but I have seen new hardcover copies online for as little as $\$ 24$. Even at list, though, it seems a good value. 